American Journal of Pharmaceutical Education 2018; 82 (10) Article 7041.

\title{
COMMENTARY
}

\section{Successful Strategies to Spotlight Achievement and Recognize Excellence}

\author{
Cynthia J. Boyle, PharmD, BSPharm \\ University of Maryland School of Pharmacy, Baltimore, Maryland \\ Submitted February 28, 2018; accepted July 19, 2018; published December 2018.
}

Keywords: award, strategy, champion, nomination, recognition

Recognition can be a powerful motivator and is one approach to reward excellence among students, faculty, practitioners, and stakeholders of schools/colleges of pharmacy. In academia, we are fortunate to get to know accomplished and outstanding people from a wide spectrum of endeavors. We are often approached to write awards nominations or letters of support. Even though we may prefer to promote nominations of our own colleagues, we are positioned to promote recognition of deserving individuals' achievements in many areas. One of the most challenging and rewarding opportunities is championing an award nomination packet.

Many of us have mentored a colleague toward promotion, which is comparable to compiling evidence and supporting criteria of excellence. I regularly nominate colleagues for state-based awards in pharmacy organizations and governmental units and have championed nomination packets for fellow designations in national organizations and awards. Often, I have served on local and national awards committees and have helped to refine national awards criteria for three national associations. Also, I created and supported two honorary degree nomination packets, which were routed systematically through university administrative levels and up to the University System of Maryland that approved the selections. My nominees are not always selected, but many have been honored.

\section{General Guidance}

How should one approach a well-organized and well-written nomination for an award? While there is little guidance in published literature, award-specific websites offer abundant suggestions for compelling nominations. ${ }^{1,2}$ The first step is to fully review the award criteria and timeline, as well as the previous award recipients. Do you know someone who is worthy of consideration and who meets the criteria?

Corresponding Author: Cynthia J. Boyle, University of Maryland School of Pharmacy, 20 N. Pine St., Baltimore, MD 21201. Tel: 410-706-5834. E-mail: cynthia.boyle@rx. umaryland.edu
As desirable as it could be to surprise a nominee, there is seldom an occasion when a surprise nomination is warranted, especially for national awards. Only the award candidate can provide the most up-to-date curriculum vitae $(\mathrm{CV})$ and is in the best position to describe the impact of their work. As for ideas for the best people to write letters of support, the nominee knows who could optimally support achievement of the criteria and impact. A frank discussion is also needed for the appropriate person to be the award champion, because the champion's nomination letter is the focus of the nomination. An award champion can be very effective based on firsthand experience with the nominee, but that may not always be possible. Perspectives from a variety of people help to support an award packet. A recent award nomination I championed included letters from a mentee, a protégé, a volunteer leader, a former supervisor, a renowned executive, and a former award recipient.

Plan the Award Packet. If you decide to champion a nomination, you must be able to commit the time and effort needed along with your other roles and duties. Increasingly, awards nominations and scholarship applications require one packet to be submitted with all the required elements.

Communicate. Establish a communications plan and timeline by working back from the deadline. Build in sufficient leeway for an occasional delayed letter or technological challenges.

Spotlight Accomplishments. Work with the nominee to ensure his/her curriculum vitae (CV) is up to date and brainstorm for the best individuals to spotlight the nominee's accomplishments. If clarifications or additions are needed, the information will be more current and accurate for the letter writers and later for the awards committee.

Secure Commitments. Contact letter of support writers to secure their commitment and ability to meet the deadline. They will need to know the award purpose/ criteria and to receive the nominee's most current $\mathrm{CV}$. Instruct the letter writers where to focus based on the conversation with the nominee. It can be helpful to provide a list of previous recipients. 


\section{American Journal of Pharmaceutical Education 2018; 82 (10) Article 7041.}

Bring the $C V$ to Life. Encourage the letter writers to "bring the CV to life" rather than extensively restating information in the $\mathrm{CV}$, which is usually a component of the nomination packet. Ask them about what they can add about the efforts that went into a publication or an accomplishment. What did the nominee do that was extraordinary in bringing an accomplishment to fruition? How can the letter of support help the awards committee understand the importance of one's work?

Compile and Review. I generally reserve portions of several days to compile and review the award packet, unless the nomination portal allows periodic uploads as letters are received. I have never received a poorly written letter of support, but time might be needed to clarify or improve a letter with the author's permission. If the award allows the nominator letter and up to two letters of support, the award champion should ensure all three are provided to fully support the nomination.

Update the Team. Update your nomination team about progress. Regular reminders over 3-4 months' time help to keep the nomination on track. Even the busiest and most accomplished people are generally willing to write letters and often appreciate an occasional reminder.

Follow-up. Provide the award decision to the letter writers and encourage them to add their congratulations once the official announcement has been disseminated. If the nomination is not successful the first time, the award champion may seek additional feedback to improve the nomination. Feedback to the nominator is built into some awards processes.

\section{Award-Specific Strategy}

A nomination packet builds a case for the selection of your nominee for an honor, scholarship, or award. Start with an outline. Using the award criteria, create a framework for your letter. With the volumes of materials that may accompany a nomination, headings can help the readers understand your main points as they evaluate and score the packet. You can even introduce the letter writers and explain why you have selected them for specific criteria. Even the order of nomination paragraphs is important; if the criteria are for leadership, management, and service, the letter should be organized in the same order to make it easy for awards committee reviewers to find pertinent information. As the award champion, you may start the nomination letter draft early in the process, but it should be finalized after all the letters of support are received. You will make the case, justify your nomination, and persuade the committee by weaving in direct quotes from the letters of support to illustrate and support notable accomplishments. Briefly conclude with a summary recapping main points as reinforcement. ${ }^{1}$

\section{Unwritten Criteria}

The nominator may not have access to the scoring rubric which the awards committee members use to evaluate and score a nomination. For example, one criterion may be listed as service to the organization but would be scored in terms of specific years/examples of service up to a maximum number of points. In this way, the award criteria can be weighted. The nominator's goal is to provide enough specific, factual information in vivid, memorable language that the nominee is considered among the top-scoring candidates when the awards committee engages in selection discussions.

\section{Summary}

In any given year, awards committees may not be overwhelmed with numerous nomination packets. It is easy to understand why because of the time and personal investment needed to champion a nomination packet. For national awards, the nominations are usually competitive and high quality. Awards committee members commit to confidential selection processes, and they fully review and rate nomination packets. A considerate award nomination champion will supply complete information, avoid unnecessary redundancies, and comply with directions. Champions experience professional satisfaction and a sense accomplishment when their nominees are selected. Time to celebrate.

\section{REFERENCES}

1. Askew R. Writing a winning nomination. Mississippi RN. 2006:13.

2. How to: write a compelling nomination. University of North Carolina Wilmington. https://uncw.edu/d2la/RECOGNIZE/ documents/HowtoWriteaCompellingNomination.pdf. Accessed March 21, 2018. 